\title{
Cultural Influences on Cognitive Representations of Conflict: \\ Interpretations of Conflict Episodes in the United States and Japan
}

\author{
Michele J. Gelfand, Lisa H. Nishii, \\ Karen M. Holcombe, and Naomi Dyer \\ University of Maryland
}

Ken-Ichi Ohbuchi and Mitsuteru Fukuno

Tohoku University 


\begin{abstract}
This article integrates theory from the cognitive tradition in negotiation with theory on culture and examines cultural influences on cognitive representations of conflict. The authors predicted that although there may be universal (etic) dimensions of conflict construals, there also may be culture specific (emic) representations of conflict in the United States and Japan. Results of multidimensional scaling analyses of U.S. and Japanese conflict episodes supported this view. Japanese and Americans construed conflicts through a compromise versus win frame (R. L. Pinkley, 1990), providing evidence of a universal dimension of conflict construal. As the authors predicted, Japanese perceived conflicts to be more comprom/se-focused, as compared with Americans. There were also unique dimensions of construal among Americans and Japanese (infringements to self and giri violations, respectively), suggesting that identical conflict episodes are perceived differently across cultures.
\end{abstract}


Conflict is ubiquitous and has been the subject of scientific inquiry throughout the past century. Indeed, conflict is likely found in most human civilizations and across historical periods. Nevertheless, within the discipline of psychology, the scientific study of conflict has been limited primarily to U.S. samples and may be laden with individualistic assumptions (Gray, 1994). In this respect, our understanding of conflict remains largely "culture-bound" (i.e., has its roots in Euro-American thought and traditions) and "culture-blind" (i.e., tends to ignore culture in its theories and research; Erez, 1994; Smith \& Bond, 1999). In an era of increasing globalization, an understanding of cultural influences on conflict has both theoretical and practical importance. The purpose of this research is to shed new light on the relationship among culture, cognition, and conflict by integrating theory from one of the main theoretical traditions in negotiation, the cognitive tradition (Neale \& Bazerman, 1991; Pinkley, 1990), with theory on elements of culture, namely, individualism-collectivism (Markus \& Kitayama, 1991; Triandis, 1995). More specifically, the question that guided this research was: Are the dimensions used to evaluate conflict situations universal (etic), or are they culture-specific (emic)?

The general proposition advanced in this article is that although there may be universal dimensions of conflict construals, disputants' cognitive representations are influenced by the conception of the self that is dominant in the surrounding culture (individualistic vs. collectivistic), and thus, cognitive representations of conflict vary across cultures. We expected that identical conflict episodes would be construed differently in two cultures, the United States and Japan, which have been shown to systematically differ along the individualism-collectivism dimension (Hofstede, 1980; Markus \& Kitayama, 1991; Schwartz, 1994; Triandis, 1995). In what follows, we first discuss the nature of cognition in conflict situations and the dimensions of conflict construal that have been found in previous research among disputants in the United States. We then consider the implications of culture for cognitive 
representations of conflicts and discuss the nature of the self and cognition in the United States and Japan. Finally, we describe a multidimensional scaling (MDS) study that investigated cultural influences on conflict construals.

\section{Cognition in Conflict and Negotiation}

Negotiation has been defined as "the deliberate interaction of two or more complex social units which are attempting to define or redefine the terms of their interdependence" (Walton \& McKersie, 1965, p. 3). According to the cognitive tradition (Bazerman \& Neale, 1983; Thompson, 1990), negotiation processes and outcomes can be best understood when negotiations are viewed as a cognitive decisionmaking task in which negotiators construct mental representations of the conflict situation, issues, and their opponents. In other words, bargainers enter the negotiation with cognitive representations, or conflict frames, which serve to impart meaning or make sense of the conflict situation (Pinkley, 1990; Putnam \& Holmer, 1992) and which often take place below the level of conscious awareness (Drake \& Donohue, 1994). Frames are akin to schemas, or organized knowledge structures that guide negotiators' selection and interpretation of information, and thus lead to a particular focus on some characteristics of a conflict situation while ignoring others. In essence, because conflict situations often contain many elements and because negotiators have limited information-processing capabilities (Neale \& Bazerman, 1991), frames enable negotiators to render some of the elements to the "figure" and others to the "ground" (Goffman, 1974).

Consistent with this view, research in the cognitive tradition has concentrated on identifying the specific ways in which conflicts are defined or framed. Over the past two decades, a number of studies in the United States have demonstrated that conflict frames are reliable and can be systematically 
described (see Pruitt \& Carnevale, 1993, for a review). Most recently, in a landmark study that integrated and extended previous research on conflict frames (Bazerman \& Carroll, 1987; Kelley \& Thibaut, 1978; Sheppard, Blumenfeld-Jones, \& Minton, 1987; Wish, Deutsch, \& Kaplan, 1976), Pinkley (1990) demonstrated that conflict frames generally fall into one of three independent dimensions: compromise versus win, intellectual versus emotional, or relationship versus task.

The first frame, compromise versus win, reflects the emphasis that negotiators place on the nature of the blame in the dispute (Pinkley, 1990). Specifically, negotiators with a compromise frame perceive that both parties are blameworthy and see the need for both parties to compromise or find a mutually acceptable agreement. By contrast, negotiators with a win frame have a zero-sum perspective; they place the blame on one party and focus on the need for one party to concede (Pinkley, 1990; Thompson \& Hastie, 1990). This frame has been discussed widely in the psychological literature and has also been referred to as correspondence versus non-correspondence (Kelley \& Thibaut, 1978), cooperative versus competitive (Wish et al., 1976), and right versus wrong (Sheppard et al., 1987). Indeed, this frame has been found to characterize negotiators in a number of empirical studies (see Thompson, 1990), suggesting that the nature of blame and the question of whether compromise is possible are of central importance in construing conflicts.

The second frame, intellectual versus emotional, focuses on the degree to which negotiators attend to the affective aspects of the conflict. Negotiators with an intellectual frame concentrate on the facts, thoughts, logic, and actions involved in the conflict (i.e., who did what to whom and when). Negotiators with an emotional frame focus on the feelings involved in the conflict, such as anger, suspicion, frustration, and sadness (Pinkley, 1990).1 Finally, the third type of conflict frame, relationship versus task, focuses on the variation in the extent to which negotiators focus on the ongoing relationship with the other party (Pinkley, 1990). Negotiators with a relationship frame concentrate on 
the relatedness that exists between the parties (e.g., trust). By contrast, negotiators with a task frame focus on the most efficient way to achieve desired ends, such as material benefits, and these concerns are viewed as external to the specific relationship.

Whereas the existence of conflict frames has generally been undisputed, the factors that contribute to the development of particular conflict frames have received scant attention. Although researchers have suggested that disputants can hold different interpretations of the same conflict situation because of differences in frames (Pinkley, 1990), it is less clear how these differences actually arise. If discrepant interpretations of the same conflict can inhibit effective conflict resolution (Drake \& Donohue, 1994), it is important to be able to predict when this will occur. In this research, we focus on cultural influences on cognitive representations of conflict episodes. Specifically, we propose that disputants' cognitive representations are shaped by the conception of the self that is dominant in the surrounding culture (individualistic vs. collectivistic).

To date, much research has illustrated that self-structures have a pervasive influence on perception, memory, and inference (Fiske \& Taylor, 1991). In particular, people notice information that is relevant to self-construals in themselves and in others (Kihlstrom \& Klein, 1994), and self-construals are critical in lending meaning to social situations (Fiske \& Taylor, 1991). Accordingly, we expected that the self, and associated values, influences the selection and interpretation of information and frames assumptions about what is important in conflict situations. Moreover, because the nature of the self varies tremendously across cultures, we expected that there would be cultural differences in cognitive representations of conflicts (see also Tinsley \& Brett, 1997). As we discuss below, we expected that (a) the dimensions on which conflicts are construed may vary across cultures and (b) even when dimensions of construal are invariant across cultures, there will be mean differences in perceptions along such dimensions. 


\section{Culture and Cognitive Representations of Conflict}

Culture has been very broadly defined as the human-made part of the environment (Herskovits, 1955), consisting of both objective (e.g., tools, housing) and subjective elements, or a "group's characteristic way of perceiving its social environment" (Triandis, 1972, p. 3). Elements of subjective culture are often interrelated and form unique cultural syndromes (Triandis, 1989), which reflect basic issues that societies must confront in regulating human activity (Schwartz, 1994).

One fundamental issue that all societies must confront is the nature of the relationship between the individual and the group, which has been broadly referred to as individualism and collectivism (Hofstede, 1980; Triandis, 1995). Generally speaking, this dimension contrasts the extent to which people are autonomous individuals versus embedded in groups (Schwartz, 1994). It is now conceived of as one of the primary dimensions by which cultures can be differentiated, and there is increasing evidence that the nature of the self, and consequently information processing, varies across individualistic and collectivistic cultures (Markus \& Kitayama, 1991; Triandis, 1989).

Specifically, in individualistic cultures, such as the United States, independent self-construals, generally speaking, become highly developed and are highly accessible (Markus \& Kitayama, 1991; Triandis, 1989). The self is construed as detached from collectives and is defined in terms of specific accomplishments, attitudes, and abilities. The cultural ideal is to be separate from others, to express one's uniqueness, and to maintain a positive self-image (Markus \& Kitayama, 1991; Shweder\& Bourne, 1982). In such cultural systems, the self is thought to be a free agent (i.e., is entitled to do what it wishes; Landrine, 1995), and social responsibilities are more a matter of choice than obligation (Markus, Kitayama, \& Heiman, 1997; Miller, Bersoff, \& Harwood, 1990). Not surprisingly, research has found that 
in individualistic cultures, such as the United States, there is a strong emphasis on values of selfdetermination, self-actualization, freedom, competition, and privacy (Triandis, McCusker, \& Hui, 1990). Within such cultural systems, conflict is natural, and parties are often susceptible to self-serving and competitive biases (Thompson \& Loewenstein, 1992), which is not surprising given the cultural task of self-enhancement.

In the United States, such emphases have their historical roots in the Enlightenment and Kantian notions of individual reason and free will (Markus et al., 1997). Furthermore, the emphasis on the independent self is grounded in an ontological tradition that emphasizes a "Cartesian" split self, wherein the self is contrasted against the external environment, and dichotomies between "subject and object, emotion and reason, [and] feeling and thought" are seen as natural (Cushman, 1995, p. 401; see also Lebra, 1984, and Markus et al., 1997). Indeed, this split is reflected in the earlier discussion of conflict frames in the United States. As in the larger cultural context, research has found that disputants in the United States separate emotional and intellectual components, as well as relationship and task components, in construing conflict situations (Pinkley, 1990, 1992). Likewise, conflict practitioners emphasize the importance of separating the person from the problem and separating the facts from the emotions in the conflict (Fisher \& Ury, 1981; Raiffa, 1982), which is consistent with the independent self.

By contrast, in collectivistic cultures, such as Japan, the interdependent self, generally speaking, becomes highly developed and is highly accessible (Markus \& Kitayama, 1991; Triandis, 1989). In contrast to the independent self, the interdependent self is largely defined in terms of relationships and is conceived of as fundamentally embedded in, and not separate from, the larger social context. In Japan, for example, the self is situated in terms of particular roles and statuses that prescribe specific duties, obligations, and commitments, which are enacted to help preserve harmony (Geertz, 1973; Landrine, 1995; Marsella, DeVos, \& Hsu, 1985). Meeting social responsibilities and obligations (gin) in 
one's social position is a moral imperative (Miller et al., 1990), and one must maintain one's face (taimen) and reputation at all costs (Ho, 1973; Kim, 1994). As Landrine (1995) so cogently argued, "Role failure or violation is the loss of the self in socio-centric cultures; it is the existential, social, and psychological death of the individual" (p. 755). Not surprisingly, research has found that collectivist cultures place a strong emphasis on values of adherence to obligations, maintaining harmony, preserving face, and cooperation (Triandis et al., 1990). Within such cultural systems, although conflict is inevitable (Krauss, Rohlen, \& Steinhoff, 1984), it is viewed as disruptive, and as a result, parties are attentive to keeping conflicts covert, rather than overt (Lebra, 1984; Ohbuchi \& Takahashi, 1994).

In Japan, the interdependent self has its historical roots in Confucius's moral-political philosophy as well as Buddhist teachings of sacrifice and the submerged self (Markus et al., 1997). It is notable that such traditions are grounded in a non-Cartesian epistemology, wherein the self is not fully distinguishable from the environment and wherein dichotomies of subject-object and intellect-affect are not at all natural (Cushman, 1995; Markus et al., 1997). Indeed, although conflict frames have not been investigated in Japan, consistent with a view of the interdependent self, Ting-Toomey (1994) theorized that conflict events in this system take on a "face maintenance model," in which parties focus on the relational and affective aspects of the conflict as indistinguishable from the task and intellectual aspects of conflict itself. In other words, unlike in the United States, in Japan, where the self is interdependent and is intertwined with others, it is difficult for individuals to separate the facts (i.e., intellectual aspects) of the conflict from the emotions of the parties, or the relationship with the other party from the task (Cohen, 1991; Ting-Toomey, 1990, 1994). Put simply, in Japan, "the conflict issue and the conflict person are the same, hardly separable from each other" (Ting-Toomey, 1990, p. 78). 


\section{Hypotheses}

The central purpose of this article was to expand on previous research within the cognitive tradition in conflict and negotiation and specifically to investigate universal and culture-specific dimensions of conflict frames. On the basis of the preceding discussion, we predicted that there would be differences in cognitive representations of conflict episodes in individualistic cultures (i.e., the United States) and collectivistic cultures (i.e., Japan) that are reflective of differing emphases on the independent and the interdependent self, respectively. First, on the basis of research by Pinkley (1990), we expected to replicate conflict frames previously found in the United States among American participants.

Hypothesis 1: Conflict frames found in previous U.S. research, namely, compromise versus win, intellectual versus emotional, and relationship versus task, will be replicated among American participants.

Second, we assessed whether these specific frames, which have been investigated exclusively in the United States, would be found in the cultural context of Japan. We reasoned that Japanese would also be attentive to which party holds responsibility for the conflict (i.e., would use a compromise vs. win frame), because such attributions inform disputants' judgments of how the conflict should be resolved-which is a key concern in the Japanese context, given the importance of harmony (Lebra, 1984). At the same time, on the basis of the notion that the conflict itself is often seen as inseparable from the person in Japan (Cohen, 1991; Ting-Toomey, 1990, 1994), we did not expect that such distinctions as relationship-task and intellectual-emotional would be as salient among Japanese in construing conflict episodes (i.e., they would not be dimensions through which conflicts are construed). 
Hypothesis 2: Out of previous frames found in the United States, only the compromise versus win frame will generalize to Japanese participants.

Furthermore, on the basis of the importance of harmony and cooperation in the Japanese context, we anticipated that even if Japanese and Americans use the same dimension of compromise versus win to construe conflicts, Japanese would perceive the same conflicts to be more about compromise (i.e., having mutual blame) than would Americans. In other words, although the same metric may be used to construe conflicts, there will be mean differences in perceptions of cooperation along this continuum that are consistent with the nature of the self discussed.

Hypothesis 3: The same conflict situations will be perceived differently in the United States and Japan along the compromise versus win dimension. Specifically, conflicts will be construed more in terms of compromise in Japan than in the United States.

Finally, on the basis of the previous discussion of the nature of the self in Japan, we also predicted that there would be unique dimensions of conflict construal that arise among Japanese in construing conflicts that have not emerged in previous research.

Hypothesis 4: Cognitive representations among Japanese will reflect the degree to which obligations to roles and duties have been fulfilled (.gin) and face (taimen) has been maintained, as well as the extent to which the conflicts are covert versus overt.

To test these hypotheses, we used MDS. This method is ideally suited for our purposes because it enables one to locate stimuli (i.e., conflict episodes) in a spatial configuration or "map" and illuminates the underlying dimensions of construal that participants use to represent the conflicts. Moreover, this inductive technique allows for the illumination of cognitive representations that may not be in conscious awareness (Pinkley, 1990). 
Furthermore, consistent with cross-cultural theory (Triandis, 1983), we used a combined emic and etic approach in our MDS design and analysis. Specifically, we examined how conflict episodes that were generated by samples in both the United States and Japan were viewed by both American and Japanese participants. This design produced four separate MDS spaces: (a) American cognitive representations of U.S. conflicts, (b) Japanese cognitive representations of U.S. conflicts, (c) American cognitive representations of Japanese conflicts, and (d) Japanese cognitive representations of Japanese conflicts. This design enabled us to use stimuli that were derived naturally in each culture (in the spirit of an emic approach) yet also allowed for cross-cultural comparisons of cognitive construals of identical conflict episodes (in the spirit of an etic approach).

In addition to being a culturally sensitive design, this approach has several advantages. First, it enabled us to examine whether participants used similar frames to interpret conflicts generated in both their own and other cultural contexts. On the basis of the theory presented previously, we expected that Japanese participants would consider issues of overtness-covertness and issues of face and role obligations as salient when viewing their own conflicts as well as U.S. conflicts, given that people perceive implications for their values in external stimuli (Gibson, 1979). At the same time, because everyday routines, practices, and social episodes vary across cultures (Kitayama, Markus, Matsumoto, \& Norasakkunkit, 1997), we reasoned that it is possible that conflicts generated in the two cultures may have unique features. Because contextual features of conflicts activate frames (Pinkley, 1992), we also explored the possibility that conflict frames (e.g., overt-covert) may be activated more clearly (i.e., as a dimension through which conflicts are perceived) when members of a culture are viewing socially constructed situations generated in their own cultural context. In other words, Japanese participants may perceive that U.S. conflicts have elements of overtness or covertness, yet it may not be a salient dimension being used to characterize the conflicts. In contrast, when Japanese participants are viewing 
Japanese conflicts, such issues may become more activated, and, as such, a salient dimension may result. Because this was more exploratory in nature, we did not make any explicit a priori hypotheses regarding the interaction of culture, context, and construals.

Finally, this design enabled us to illuminate strong universals (Lonner, 1980) of conflict construal. That is, a dimension of construal that is found across all four MDS spaces provides evidence for construals that exist regardless of cultural background and regardless of the origination of the conflicts. In sum, this methodology and design allowed us to test for both universal and culture-specific aspects of conflict construals across samples and conflicts.

\section{Method}

Following Pinkley (1990), the data for this study were collected in three phases.

\section{Phase 1: Generation of Conflict Episodes}

The respondents in Phase 1 consisted of 144 students from the United States and 207 students from Japan who received course credit for their involvement in the study. The samples were highly similar with regard to age $(M=20.0$ years in the United States and $M=19.8$ years in Japan) and gender (45\% male, 54\% female, and $1 \%$ unknown in the United States; $54 \%$ male and $46 \%$ female in Japan).

On the basis of methods used in previous research (Pinkley, 1990), participants were asked to write a description of one conflict that they had experienced in the recent past. They were told they could describe any incident they chose, regardless of its nature, the type of relationship, or the degree of severity of the dispute. Participants were asked to describe the conflict situation in terms of the following two questions: (a) Briefly, what is the conflict really about? and (b) What is at the heart of the conflict? In both countries, instructions were given in the native language, English or Japanese. All 
materials were first translated into Japanese and then back translated into English by another translator to check for discrepancies (Triandis, 1983).

To ensure that the MDS task, which requires comparisons across all conflict stimuli, was manageable from a cognitive load perspective, 28 conflict episodes were selected from each culture. We had three criteria for the inclusion of episodes that were based on cognitive load concerns, readability of the episode, and relevance across both cultures. Specifically, selected episodes had to be (a) brief (two or three sentences), (b) clear and unambiguous as to the exact nature of the conflict, and (c) relevant in both cultural contexts. After conflicts were eliminated on the basis of these criteria, we randomly chose 28 conflicts in the United States and 28 conflicts in Japan for the MDS component of the study (Phase 2).2

Phase 2: MDS Procedure

A total of 224 participants received course credit for their involvement in this portion of the study (94 students from the United States and 130 students from Japan). The samples were highly similar with respect to demographics such as age $(M=20.5$ years in Japan and $M=21.2$ years in the United States) and gender (49\% male, 47\% female, and 4\% unknown in Japan; $41 \%$ male, $54 \%$ female, and $5 \%$ unknown in the United States).

For Phase 2, we asked respondents to engage in a multidimensional sorting task to illuminate the dimensions necessary to describe their construals of the conflicts generated in Phase 1. All participants were given a set of 28 index cards, each of which contained a description of a conflict situation. Students in both the United States and Japan were randomly assigned to sort either the U.S. conflict episodes or the Japanese conflict episodes. Participants were completely unaware of the source of the conflict episodes (i.e., Japan or the United States) as well as the cross-cultural nature of the study. 
Per Forgas and Bond (1985), participants were asked to sort the conflict cards into as many piles as they desired on the basis of their perceived similarity. Thereafter, a conflict episode by conflict episode ( $28 \mathrm{X}$ 28) diagonal matrix of dissimilarities was created for each of the U.S. and Japanese participants (Kruskal \& Wish, 1978). Consistent with Kruskal and Wish, U.S. and Japanese participants' judgments were aggregated (separately for U.S. and Japanese conflicts), resulting in four triangular matrices for the MDS analyses. Kruskal's measure of stress or goodness-of-fit index specified the number of dimensions needed to represent the stimulus space. This measure indicates how well distances in the configuration reflect the actual proximities in the data from which the space was derived. Finally, to help interpret these dimensions, we gathered additional data in Phase 3.

\section{Phase 3: Unldimensional Item Ratings for Labeling of Dimensions}

After completing the task in Phase 2, all of the participants from Phase 2 rated the conflicts that they had just sorted according to a number of unidimensional items to assist in the labeling of the dimensions. These items were derived from previous studies of conflict construal conducted in the United States (e.g., Pinkley, 1990). However, because previous research was done only in the U.S. context, we included additional items that were based on an in-depth examination of articles on Japanese culture (Lebra, 1984; Markus et al., 1997) and from themes that were discussed in Phase 1 ("What was the conflict about?"; e.g., coverrness, obligations, harmony, face).

A total of 21 items were included in Phase 3, which are listed in Table 1. Because of time restrictions and the cognitive load of the ratings ( 28 conflicts $X 21$ ratings would require 588 ratings), participants were randomly assigned to rate either the first 14 conflicts or the last 14 conflicts on the 21 unidimensional items. Per Kruskal and Wish (1978), we used multiple regression analyses to examine how well the location of each conflict on these unidimensional items was predicted by its location in the multidimensional space. In statistical terms, the unidimensional item values were regressed onto the 
coordinate values in the chosen configuration. For an item to be useful in interpreting the space, it must have a significant multiple correlation (i.e., at $\mathrm{p}<.05$ ), which indicates that the configuration "explains" the item well, and it must have a significant beta weight (standardized regression coefficient) on a dimension, indicating that the scale corresponds to the attributes in the multidimensional space (Kruskal \& Wish, 1978). The dimension on which it loads the highest is generally used for interpretative purposes (Kruskal \& Wish, 1978). If an item loads on all dimensions equally, however, it is not as useful for labeling the dimensions (i.e., is less clear). In addition to these items, as per Kruskal and Wish, we also inspected the order of the actual conflicts on each dimension in conjunction with the regression analysis for purposes of labeling.

\section{Results}

Figure 1 presents MDS stress values for one through five dimensions for all of the multidimensional spaces derived through SPSS. As recommended by Kruskal and Wish (1978), an elbow test suggested that stress values did not decrease substantially from the three- to four-dimensional solutions, yet they did decrease substantially from the two- to three-dimensional solutions for all of the MDS spaces. Furthermore, the three-dimensional solution allowed for the most comprehensible interpretations for all of the MDS solutions when the results from the regression analysis of the ratings compiled from Phase 3 were examined. As such, on the basis of multiple sources of data, the threedimensional solution was deemed the best description of the data in all spaces.3

\section{Overview of Dimensions of Construals in All MDS Spaces}

Table 2 presents the labels of the dimensions in all four spaces. The results provided partial support for Hypothesis 1, as American participants used the compromise versus win frame and the 
intellectual versus emotional frame in construing both the U.S. and Japanese conflicts. Consistent with Hypothesis 2, Japanese construed both sets of conflicts through a compromise versus win frame. Thus, the results showed that compromise versus win was a strong universal of conflict construal across samples and conflicts. Consistent with Hypothesis 3, as we discuss below, comparisons of American and Japanese perceptions along the compromise versus win dimension illustrated that Japanese perceived both the U.S. and the Japanese conflicts to be more about compromise than did Americans.

Furthermore, in support of Hypothesis 4, Table 2 illustrates a clear emic dimension of conflict construal used by Japanese in construing both U.S. and Japanese conflicts, namely, giri violations (duty to repay obligations vs. duty to maintain one's reputation). Finally, in support of the notion that the context can also be important in producing conflict frames, the results found that different conflicts (U.S. or Japanese) activated different emic dimensions of construal among Americans and Japanese. U.S. conflicts activated an infringements-to-self frame among Americans but a differentiation-of-self-fromothers frame among Japanese. Japanese conflicts activated an overt versus covert frame among both sets of respondents, although as we discuss below, this frame had differences in meaning among the samples.

Next, we elaborate on the labeling of each of the dimensions in each of the MDS spaces. Table 1 presents the multiple correlations for each of the items for the U.S. and Japanese conflicts as viewed 
by American and Japanese participants. If and only if an item was significant, we then examined the dimension on which it had the highest loading (Kruskal \& Wish, 1978), which can be found in Table 3 (for U.S. conflicts) and Table 4 (for Japanese conflicts).

\section{U.S. Conflicts: American Participants}

Dimension 1. Dimension 1 was labeled compromise versus win, which has been found in previous research in the United States (Pinkley, 1990, 1992). The items that were useful in interpreting the high end of this dimension included "Requires a compromise or mutual cooperation" $(p<.05)$ and "Caused by both parties (both parties are responsible or to blame for the conflict)" $(p<.01)$. Conflict

INSERT TABLE 2 HERE

episodes at this end of the continuum reflected the need for mutual cooperation and shared responsibility. Additional items defining this end of the dimension included "Involves distinctions between ingroups and outgroups" and "Is about preserving harmony" (ps $<.01$ ). Items at the low end of this dimension included "Requires a concession by one party (one party is right and the other is wrong)" $(p<.01)$, "Caused by one of the parties (one party is responsible for the conflict or is to blame)" $(p<$ $.01)$, and "Reflects moral considerations" ( $p<.01)$. Conflict episodes at this end of the continuum reflected a win-lose perspective, whereby one party was blameworthy, had gained at the other's expense, and needed to unilaterally concede so as to resolve the conflict.

INSERT TABLE 3 HERE

Dimension 2. Dimension 2 was labeled intellectual versus emotional, with the former focusing on the facts and thoughts and the latter focusing on the emotional components of a conflict, which 
replicates Pinkley's (1990) research. The conflicts on the low end of the dimension focused on the facts associated with a conflict, such as who did what to whom, and what the consequences of specific actions were. These conflicts typically involved factual descriptions of actions of one party that violated a social contract. The items loading on this end of the dimension included "Intellectual (the focus was on facts, logic)" ( $p<.01)$ as well as "Individual's sense of duties/obligations," "Social norms," and "Clash between individual and group interests" (ps < .01). By contrast, the conflicts on the positive end of the dimension focused on the emotional nature of the conflicts, all of which were characterized by feelings of jealousy, pain, and frustration. Not surprisingly, the relevant items loading on this end included "Emotional (focus on the feelings involved)" ( $p<.01)$ and "Involves feelings of guilt or shame" $(p<.01)$.

Dimension 3. Dimension 3 was labeled infringements to the self (nonmaterial-intangible vs. material-tangible belongings). Along this dimension, differentiations were made between conflicts that involved infringements made to nonmaterial (intangible) aspects of the self (e.g., autonomy, freedom of decision and choice) and infringements made to one's rights regarding material (tangible) belongings of the self (e.g., one's job, money, property). More specifically, conflicts at the low end of this dimension involved situations in which one person interfered with another and challenged the person's independence and freedom to make decisions. Such conflicts reflected infringements to the self that were of a nonmaterial nature. The items that loaded on the negative end of the dimension included "The conflict involves threats to one's independence of thought or freedom of choice" $(p<.01)$ and "The conflict revolves around challenges to one's autonomy" $(p<.01)$. By contrast, conflicts at the opposite

\section{INSERT TABLE 4 HERE}

end of this dimension focused on the denial of something that was rightfully deserved, resulting in the loss of material belongings. They included, for example, a conflict in which one person wrongfully lost his or her job and a conflict in which one was denied a raise of which he or she was deserving. Items that 
loaded on the positive end of the dimension included "The conflict reflects a direct infringement of one person's personal rights" $(p<.05)$ and "The conflict involves what one person feels they are rightfully entitled to" ( $p<.01)$. Because this dimension was not found in any other multidimensional space (see Table 2), this dimension reflects a clear emic theme among Americans viewing their own conflicts.

\section{U.S. Conflicts: Japanese Participants}

Dimension 1. Dimension 1 was labeled compromise versus win and was very similar to the American participants' cognitive representations of U.S. conflicts (Dimension 1). Items that were identical to the American perceptions of the U.S. conflicts included "Requires a compromise or mutual cooperation" ( $p .01)$ and "Caused by both parties" $(p<.01)$ for the positive end of the continuum and "Requires a concession by one party" ( $p<.01)$, "Caused by one of the parties" $(p<.01)$, and "Reflects moral considerations" $(p<.01)$ for the negative end of the dimension. Japanese participants also viewed the compromise end of the continuum as being "Intellectual" $(p<.01)$ and the win end of the continuum as being "Related to guilt and shame" $(p<.01)$. Given that this dimension was found in both samples, we examined whether there were cultural differences in the degree to which conflicts were perceived along this dimension. As we predicted (Hypothesis 3), Japanese participants perceived conflicts as involving mutual blame and compromise more than did American participants, $t(\backslash, 114)=5.54, p<.01$.

Dimension 2. Dimension 2 was labeled giri violations (duty to repay obligations vs. duty to maintain one's reputation) and reflected the differentiations that Japanese made regarding failures to fulfill duties and obligations in one's social position. Giri is an emic Japanese concept referring to obligations, which, as discussed by Benedict (1946), are divided into two distinct types: obligations to repay others versus obligations to protect or clear one's reputation. These distinctions were clearly 
evident in the construals of U.S. conflicts. Specifically, conflicts falling on the low end of this dimension focused on the failure of one party to fulfill obligations to others, such as contributing one's fair share to work, which was referred to as "giri to the world" by Benedict (1946, p. 116). The item most highly related to this end of the continuum was "Revolves around one's sense of duties and obligations" ( $p<$ .01). Conflicts with high scores on this dimension focused on a different type of giri violation, namely, the failure to maintain one's reputation and social face, or what Benedict (1946) discussed as "giri to one's name" (p. 116). They included cases in which one party failed to protect his or her reputation from harm. The items that loaded on this end of the dimension included "Involves considerations of honor, reputation, or dignity (i.e., saving face, giving face)" and "Involves a confrontation (is out in the open)" (ps $<.01)$.

Dimension 3. Dimension 3 was labeled differentiation of self from others (communal vs. exchange relationships). Along this dimension, distinctions were made between conflicts in which a person was disobeying and separating from others with whom he or she had communal relationships (e.g., family; negative pole) and conflicts in which a person was setting himself or herself apart from others in exchange-oriented relationships (e.g., with coworkers and friends; positive pole), which caused a disruption in harmony. Specifically, conflicts on the positive end of the dimension involved situations in which one party elevated himself or herself above coworkers and friends (e.g., within exchange relationships). The primary item that loaded on this end of the dimension included "Preserving harmony between individuals or within groups" ( $p$.01). In addition, these conflicts were seen as "Covert (hiding true feelings)" ( $p<.01$ ), illustrating that Japanese participants perceived these issues to be relevant in perceiving U.S. conflicts. By contrast, conflicts with low scores reflected situations in which a person was doing his or her own thing and resisting the wishes of parents, siblings, or both (e.g., within communal relationships). In sum, the ordering of the conflicts and the items illustrated a concern with individuals 
who were set apart from others and not fitting in with others, be it with close others or with friends and colleagues. Overall, this dimension coincides well with the Japanese proverb "the nail that sticks up gets hammered down."

Japanese Conflicts: American Participants

Dimension 1. Dimension 1 was labeled compromise versus win. As in the previous results, the items that were useful in interpreting the positive pole of this dimension included "Requires a compromise or mutual cooperation" ( $p<.01)$ and "Caused by both parties" $(p<.01)$. Conflicts with high scores on this dimension focused on differences in behavioral styles and attitudes, with both parties sharing responsibility for the conflict. In addition, American participants perceived that these conflicts were related to "Threats to one's independence" $(p<.01)$ and "Challenges to one's autonomy" $(p<.01)$, themes that were also important in Americans' construal of U.S. conflicts. At the other end of the continuum, conflicts with low scores reflected a win perspective, in which one party was perceived as blameworthy, had gained at the other's expense, and was responsible for conceding. Items useful in interpreting the negative pole of this dimension included "Caused by one of the parties" $(p<.01)$, "Requires a concession by one party" ( $p<.01)$, "Issues of morality" $(p<.01)$, "Involves considerations of honor" ( $p<.01)$, and "Involves ingroups and outgroups" $(p<.01)$.

Dimension 2. The second dimension was labeled intellectual versus emotional and was very similar to the American participants' construal of U.S. conflicts (Dimension 2). Specifically, conflicts on the low end of the dimension focused on the facts associated with a conflict, such as who did what to whom, and often pertained to a contract with someone of senior status. Although very similar to the intellectual versus emotional dimension that was found among American respondents viewing U.S. 
conflicts, the importance of status was salient when American participants viewed Japanese conflicts. The most important items loading on this end of the continuum included "Intellectual" $(p<.01)$ and "Involves status" $(p<.01)$ as well as "An individual's sense of duties and obligations" $(p<.05)$. By contrast, the conflicts on the other end of the dimension were focused on the emotional nature of the conflict. They included conflicts over a loss of trust, hurt feelings, betrayal, and feelings of rejection, often provoked by inappropriate behavior. The items associated with this end of the dimension included "Emotional" ( $p<.05)$ and "Social norms" ( $p<.05)$.

Dimension 3. Dimension 3 was labeled overt versus covert. The items relevant to interpreting the positive end of this continuum included "Covert (hiding true feelings)" $(p<.01)$, "Interpersonal (problems with the relationship)" ( $<<.05)$, and "Guilt/shame" $(p<.01)$. Conflicts with high scores on this dimension involved issues that had not been aired openly and that revolved around issues of closeness and poor communication. The items useful in interpreting the other end of the continuum included "Confrontation (is out in the open)" ( $p<.01$ ) and "Nonrelationship (issues other than those dealing with the relationship)" ( $p<.05)$. Conflicts with low scores on this dimension focused on situations in which one party interfered with another as they both attempted to accomplish a goal or task, such as getting a seat at a restaurant or expecting a landlord to make repairs. Thus, the results illustrated that the overtness and covertness of the Japanese conflicts were highly salient to U.S. participants when viewing the Japanese conflicts, even though these issues were not salient when Americans were viewing the U.S. conflicts (see Table 1). Although this dimension was unexpected among Americans, this finding suggests that the Japanese stimuli strongly "engulfed" the perceiver, an issue that we discuss at more length later in this article. 
Japanese Conflicts: Japanese Participants

Dimension 1. Dimension 1 was labeled compromise versus win. Conflicts with high scores on this dimension focused on mutual responsibility and blame and on the need for both parties to compromise. Conflicts with low scores on this dimension stressed that one person was at fault and that one party needed to concede. Items that were useful in defining this dimension included "The conflict requires a compromise or mutual cooperation" and "The conflict is caused by both parties" (for the compromise end) versus "The conflict requires a concession by one party," "The conflict is caused by one of the parties," "The conflict involves moral considerations," and "The conflict involves considerations of honor, reputation, or dignity" (for the win end; ps <.01). Additional items associated with the compromise end of the continuum were "Nonrelationship issues," "Is intellectual," and "Is resolvable" ( $p s<.01)$. Additional items associated with the win end of the continuum were "Interpersonal issues" ( $p$ $<.01)$, "Social norms" ( $<<.01)$, and "Feelings of guilt and shame" $(p<.01)$. In addition, as we expected, Japanese participants perceived the Japanese conflicts as involving mutual blame and compromise more than did American participants, $\mathrm{t}(\mathrm{l}, 106)=5.54, \mathrm{p}<.01$.

Dimension 2. Similar to Dimension 2 for the Japanese participants viewing U.S. conflicts, Dimension 2 was labeled giri violations (duty to repay obligations vs. duty to maintain one's reputation). Specifically, conflicts with low scores involved failures to repay obligations to others, such as breaking a promise. As with this dimension in the U.S. conflict space, the item most highly related to this end of the continuum was "Revolves around one's sense of duties and obligations" ( $p<.01)$. Conflicts at the other end of this dimension involved failure to protect one's reputation and social face. They involved, for example, conflicts in which one party was humiliated by lies and exaggerations of others. As with the Japanese dimension when U.S. conflicts were being construed (Dimension 2), the item that related to 
this end of the dimension was "Involves considerations of honor, reputation, or dignity (i.e., saving face, giving face)" ( $p<.05)$, albeit this item also loaded on Dimension 1.

Dimension 3. This dimension was labeled overt versus covert. Conflicts with high scores on this dimension reflected that there had been a confrontation between the parties, and not surprisingly, the item useful in interpreting this dimension was "Involves a confrontation (i.e., is out in the open)" ( $p<$ .01). Conflicts with low scores on this dimension reflected that the conflict was concealed, and from the Japanese participants' point of view, this dimension was intricately tied to the nature of the status relations between parties. These construals differ from those of the U.S. participants, who viewed status issues as covarying with the "Intellectual" component of the intellectual vs. emotional dimension (see Table 4). These conflicts included, for example, situations in which a superior did something wrong but the subordinate was not able to say anything. The items loading on this end of the continuum were "Covert" $(p<.01)$ and "Involves a relationship of different status" $(p<.01)$.

\section{Discussion}

The goal of this research was to integrate theory from the cognitive tradition in conflict and negotiation research with theory from cross-cultural psychology and to empirically assess cognitive representations of conflict episodes in the United States and Japan. As we predicted, data from MDS analyses illustrated that there were both universal (etic) and culture-specific (emic) aspects of conflict construals. The results found a strong universal of conflict construal, namely, compromise versus win, across participants and conflicts. In addition, as we expected, Americans and Japanese perceived conflicts quite differently, lending to a cultural perspective on cognition in conflict. More specifically, across cultures, participants (a) used different emic frames to construe the same conflicts and (b) even 
when using the same metric of compromise versus win, perceived differences along the dimension. Finally, the results also illustrated that construals interacted with features of the context, producing interesting cultural patterns. Theoretical and practical implications are discussed below.

\section{Universal Dimensions of Conflict Construals}

First, as we predicted, the results indicate that there may, in fact, be some universal dimensions through which conflicts are construed across cultures. Regardless of the origin of the conflict, both U.S. and Japanese students construed conflicts on the basis of the nature of the blame in the conflict or, in other words, through a compromise versus win frame. Previous research has examined dimensions of conflict construal yet was based in one cultural context, the United States, with conflicts generated from American samples. The present research illustrates that the compromise versus win frame is also generalizable to a different cultural context, Japan, and with conflicts generated in Japan. More generally, our results suggest that conflict situations may universally evoke spontaneous attributions, or a search for why a conflict has occurred, and that the locus of such explanations is on who is responsible or to blame. Such attributions are likely to be salient in any conflict situation because they inform disputants of how the conflict should be resolved.

Notwithstanding the generalizability of this frame across cultures, the results also illustrate some important cultural differences in the use of the compromise versus win frame. As we expected, the results indicate that Japanese participants perceived both sets of conflicts to be more compromisefocused (i.e., having mutual blame), as compared with U.S. participants. This finding indicates that Japanese samples are cognitively predisposed to perceive mutual blame and the need for compromise, as compared with U.S. samples. Although this study was conducted with interpersonal conflicts, we 
reasoned that such differences in construals of blame could also be found in archival sources, such as newspaper accounts of conflict. To explore this possibility, we tracked a dispute on semiconductor trade that had received emphasis in both Japanese newspapers (The Daily Yomiuri and The Nikkei Weekly) and U.S. newspapers (The New York Times and The Washington Post). Nine articles published between January 1996 and June 1996 were collected from these newspapers (four in Japanese newspapers and five in U.S. newspapers). Four coders, unaware of the hypotheses in this study, coded each sentence in each article for whether it indicated that both parties were to blame ("compromise") or one party was to blame ("win"). As we expected, an analysis of variance indicated that Japanese newspapers more frequently made reference to mutual blame (compromise) than did U.S. newspapers, $(M$ Japan $=0.08$, Munited States $=0.00), F(1,8)=6.67, p<.05$. Thus, differences in perceptions of blame are found across a variety of conflict stimuli.

Such differences in the propensity to find blame are consistent with the emphasis on the interdependent and the independent self in Japan and the United States, respectively. In particular, ascribing blame to one person, even if privately in one's thoughts, is likely to be very threatening to the interdependent self, because it highlights competition and the potential disintegration of the social unit. Indeed, a popular proverb in Japan that captures this essence is "to win is to lose." In contrast, ascribing blame to both parties affords the maintenance of the social unit and is less threatening to the interdependent self. As Lebra (1984) argued, the Japanese have evolved a number of concrete mechanisms by which conflict escalation is prevented, including anticipatory management (preventing a conflict from occurring), situational code switching (being cordial only when the situation calls for it), and triadic management (involving a third party). This research also suggests another implicit mechanism, namely, cognitive framing, by which conflicts may be contained in Japan. In contrast, in the United States, a focus on winning is consistent with the independent self, for which a central task is to 
engage in self-enhancement (Markus \& Kitayama, 1991). Indeed, cultural practices and metaphors in the United States emphasize the importance of winning (e.g., "Winning isn't everything; it's the only thing!"). This study further illustrates that such notions are part of Americans' folk psychology, which are applied when Americans construe conflicts, regardless of where they originated.

Future research would benefit from examining the consequences of such different propensities in compromise versus win construals across cultures. For example, given that win frames have been associated with overconfidence and lower satisfaction among disputants (Pinkley, 1992), it would be interesting to see if overconfidence in negotiation, as a cognitive bias, is less common in other nonWestern cultures. In addition, our findings may also provide a theoretical explanation for other phenomena discussed in the literature. For example, scholars have noted that Japanese may experience anger with less frequency and intensity than Americans (Markus \& Kitayama, 1991; Matsumoto, Kudoh, Scherer, \& Wallbott, 1988), and it is possible that differences in blame attributions can partially explain this effect. Indeed, Averill (1983) and others (e.g., Weiner, 1986) have shown that anger often follows when a negative outcome is interpreted to have been caused intentionally by another. To the extent that Japanese culture is organized to avert such attributions, emotional experiences and expressions of anger are likely to vary as well. Furthermore, differences in propensities to experience anger may also help in understanding difficulties in intercultural negotiations between Americans and Japanese, a topic that has received scant empirical attention. In sum, much can be gained from an analysis of culture, construals of blame, and the experience and expression of anger within conflict and negotiation.

Likewise, these findings may be useful for understanding cross-cultural differences in procedural choice. Previous research has illustrated that people from individualistic cultures tend to prefer adversarial procedures to resolve conflicts, whereas people from collectivist cultures prefer negotiation and mediation (see Leung, 1997, for a review). Our findings suggest that among Americans, the 
preference for adversarial procedures over mediation and negotiation may be reflective of the propensity to view conflicts as "win-lose" in nature, outcomes that can arguably be best derived through adversarial procedures. In contrast, the preference for mediation and negotiation in collectivist cultures may be reflective of the propensity to see conflicts as being caused by both parties, necessitating a procedure that allows for the expression of such construals. Future research can examine whether differences in conflict construal mediate differences in procedural choice across cultures, which would provide additional theoretical power for understanding cultural differences in procedural justice.

\section{Culture-Specific Dimensions of Conflict Construal}

In addition to illuminating universal dimensions of conflict construal, the results of this study also clearly indicate that there are culture-specific dimensions of conflict construal in the United States and Japan, illustrating that the same conflicts are perceived through different lenses. Consistent with the cognitive tradition in negotiation, these results suggest that definitions of conflict are subjective in nature and are filtered through individuals' perceptual processes (Pinkley, 1990). Moreover, this research advances a cultural perspective on cognition by illustrating that conflict episodes are interpreted in ways that are consistent with prevailing cultural practices and values. As such, it suggests that definitions of conflict can also be cultural in nature.

More specifically, as we discussed previously, because of differences in conceptions of the self in the United States and Japan that are cultivated through participation in cultural practices, individuals in different cultures focus on some characteristics of conflicts and ignore others. For example, Japanese culture is organized to affirm obligations and one's position in the social system so as to maintain harmony with others (Kitayama et al., 1997; Markus \& Kitayama, 1991). In the domain of conflict, as we 
expected, Japanese participants viewed conflicts (both U.S. and Japanese) as being laden with breaches to social position, or giri violations. Consistent with an ecological view of perception (McArthur \& Baron, 1983), Japanese respondents' sensitivity to this information is adaptive in that it is needed to effectively interact in the Japanese context. More generally, such processes suggest that people also participate in the perpetuation of their culture through their own perceptions of reality.

It is interesting that although the giri violations frame was used by Japanese participants to view both sets of conflicts, there were subtle differences in the meaning of the frame depending on the conflicts being viewed (U.S. or Japanese), which suggests that the frames can interact with features of the events in the environment or context. For example, Japanese respondents viewing U.S. conflicts perceived breaches to one's social position as covarying with the level of confrontation (i.e., the degree to which the conflict was overt; see Table 3), yet this was not perceived within the giri violations dimension that was used when Japanese viewed Japanese conflicts (see Table 4). In this respect, although concerns with social position were evident in viewing both sets of conflicts, they took on slightly different characteristics depending on the features of the conflicts. Indeed, such a dynamic perspective on culture, conflict frame, and context is consistent with other results in this study. For example, consistent with the view that Japanese culture is organized to maintain harmony and minimize conflict, the results indicated that Japanese participants were attentive to the degree to which conflicts were covert (when one of the parties was hiding his or her true feelings) in both U.S. and Japanese conflicts. However, this frame was even more strongly activated by Japanese conflicts, resulting in a clear overt versus covert dimension of conflict construal. This finding suggests that frames that are implicit and cultivated within a culture are even more strongly activated when they are matched to conflicts that are part of the same cultural system. 
In much the same way, American participants perceived conflicts (both U.S. and Japanese) to be focused on infringements to the self, which is an important cultural concern through which American culture is patterned. However, this frame was more clearly activated when American participants construed U.S. conflicts. In particular, when viewing U.S. conflicts, American participants clearly differentiated conflicts involving threats to autonomy and freedom of decision from those involving direct infringements of one's rights regarding material belongings. Although Japanese conflicts did not activate a clear dimension with this theme, nevertheless, Americans still imbued other more salient dimensions (i.e., compromise vs. win) as being laden with issues of violations to autonomy when viewing Japanese conflicts. Thus, cultural themes salient to Americans were imposed on Japanese conflicts, yet they were even stronger when viewing conflicts generated in the same cultural system. Consistent with the previous analysis of Japanese participants, then, features of the conflicts accentuated already accessible frames, creating strong emic dimensions of conflict construal. It is interesting that, without culturally constructed cognitive models about the importance of individual rights and autonomy, the Japanese participants lacked the "lens" through which either set of conflicts could be interpreted as being about individual rights. Rather, in viewing U.S. conflicts, Japanese participants viewed the same conflicts as being related to differentiation of self from others, a theme that takes on much more notice in conflicts among Japanese.

One implication of this analysis is that it may be difficult for people of one culture to perceive conflict themes that are emic to another culture. However, there are some conditions when it is possible to view emic realities. In such cases, themes of conflicts from other cultures may "engulf perceivers, and provided that individuals have related concepts that are already latent in schemas from their own culture, they may construe the conflicts in culturally consistent ways. For example, American participants perceived Japanese conflicts according to an overt versus covert dimension, although these 
issues were not at all salient when American participants viewed U.S. conflicts. This is likely due to the strength of such features in Japanese conflicts (as would be expected in Japanese culture) and the likely possibility that Americans have the necessary cognitive apparatuses (i.e., understandings of covertness and overtness) to perceive such themes. Nevertheless, it is important to highlight that American and Japanese participants had different understandings of this dimension, indicating that different schematic knowledge was applied to the same conflicts. For example, Japanese, but not Americans, perceived covertness to be intricately related to status differences that existed between the parties.

Importantly, these connections (or lack thereof) are grounded in cultural experiences. In the Japanese context, individuals are socialized to respect those that have seniority, and senpai-kohai relationships are present in many levels of education and in organizations (Kashima \& Callan, 1994). As such, Japanese participants have well-developed schemas regarding how one should act in the presence of superiors, such as not second-guessing or expressing one's adversarial opinion. Thus, those conflicts that involve status differentials are likely perceived to be covert, out of cultural necessity by Japanese participants. By contrast, U.S. participants did not perceive any association between status and covertness when viewing the Japanese conflicts. In American culture, in which freedom is a central aspect of the self, individuals are free to express their opinions and emotions, even to superiors. Thus, it is not surprising, given differences in cultural experiences, that Americans and Japanese have different understandings of the same dimension.

One important implication of these results for research on culture and cognition is that cultural meanings are dynamic and change depending on the features of the context. In other words, cultural meanings are a product of both well-learned intrapersonal cognitive structures, which develop through experience, and characteristics of external events being viewed in the public world (Strauss \& Quinn, 1997). Although this view is perhaps not atypical among cognitive scientists, cross-cultural research on 
schemas focuses primarily on the former and does empirically examine the ways that schemas are dynamic-how they interact with the context. At a metatheoretical level, this view is perhaps more consistent with connectionist models of cognition than with symbolic models. Within connectionist models, schemas have "regulated improvisation...The reactions that are the output of connectionist networks are improvisational because they are created on the spot, but regulated because they are guided by previously learned patterns of associations" (Strauss \& Quinn, 1997, p. 54).4 Thus, in future theorizing, connectionist models may be ideally suited to develop more dynamic models of culture and cognition in industrial and organizational psychology (see also Lord \& Maher, 1991).

Finally, one other finding that merits attention is that although numerous dimensions were replicated from previous research among American samples (i.e., compromise vs. win and intellectual vs. emotional), the relationship versus task dimension was not found in this study. Recent research on conflict in groups has also found that task and relationship conflict can be perceived as positively, not negatively, related (Felled, Eisenhardt, \& Xin, 1999). Thus, there is growing evidence that perceptions of relational and task aspects of conflict are perhaps more complex than once thought. Future research would benefit from examining the conditions that activate different associations of these components of conflict.

\section{Practical Implications}

Practically speaking, this study empirically illustrates that identical conflicts may be perceived quite differently across cultures yet make "cultural sense" from both points of view. Given that differences in frames have been found to impede conflict resolution (Drake \& Donohue, 1994), it will be important for intercultural training programs to explicitly focus on the relationship between culture and 
cognitive representations of conflicts. Specifically, our research suggests that a helpful way of highlighting difficulties that may be encountered in intercultural settings is to illustrate how identical situations may be construed differently in different cultures. When people from different cultures apply disparate conflict frames to interpret the same conflict episodes, they may make different attributions for each other's behaviors, which may ultimately escalate the conflict. Training programs to help deal with these issues may be structured similarly to the cultural assimilator (Fiedler, Mitchell, \& Triandis, 1971). Such programs may increase on-the-job effectiveness and improve intercultural relations by helping expatriates understand the ways in which the meaning of conflicts is culturally constructed.

\section{Limitations}

All research endeavors are flawed (McGrath, Martin, \& Kulka, 1982), and this study is no exception. We used one methodology and one sample in the study of culture, cognition, and conflict, and as such, it is necessary to exercise caution in applying these results. Nonetheless, we are hopeful that the nature of these results will generalize to other settings for a variety of reasons. First, although the nature of the conflicts experienced by our samples may be somewhat different than conflicts experienced in organizational or political settings, the underlying psychological processes should be similar given that cultural themes are reproduced across diverse settings (Markus et al., 1997). Indeed, our preliminary analysis of newspaper accounts replicated some of the present results. Second, theory that is well-grounded and supported in laboratory contexts is likely to translate to real-world contexts (Locke, 1986), and recent comparisons of field and laboratory studies have found comparable effect sizes across a broad range of psychological phenomena (Anderson, Lindsay, \& Bushman, 1999). 
In addition, the present research focused only on cognition and did not assess actual conflict behaviors. Now that the culture and cognition link has been established in the conflict arena, an important next step is to directly examine the link between frames and behaviors across cultures. As definitions of reality, it seems reasonable to assume that frames may guide disputants' conflict resolution goals, which in turn guide behavioral strategies. In keeping with a cultural perspective, however, future research is needed to examine whether the same frames elicit the same goals and whether the same goals elicit the same behaviors across cultures (Gelfand \& Dyer, 2000).

Finally, it would be useful to examine frames within intercultural conflicts in future studies, because this study examined cognitions of conflicts that arose only within specific cultures. As illustrated, the same conflicts may evoke different emic conflict frames among people from different cultures. As such, it is possible that in intercultural conflicts, multiple emic frames may be activated, engendering a cultural meta-conflict (i.e., cultural conflict about the conflict). Although disputants in intercultural disputes may be more aware of differences among the parties (as compared with intracultural disputes), such conflicts may nevertheless be more difficult to resolve because of increased complexity in framing. It is also possible that intercultural conflicts may have unique features, which may evoke conflict frames not found in this research. If so, such situations may necessitate involving a third party to help elucidate and integrate differences in framing.5

\section{Conclusion}

This research illustrates that there are both universal and culture-specific dimensions of conflict construal. Theoretically speaking, this study illustrates that culture is intricately tied to cognition in conflict situations, which suggests that research on cognition in the dominant paradigm in negotiation 
research may be laden with cultural elements and should be further examined to explicate universal and culture-specific elements. Practically speaking, this study illustrates that people from different cultures can perceive identical conflicts differently, which may ultimately relate to intercultural difficulties (see also Brett \& Okumura, 1998). Future research on culture, conflict, and negotiation can further expand this perspective, which will ultimately help to build more global theories while illuminating our own and other emic realities. 
Notes

1. Although such distinctions are made by individuals in understanding conflict, this does not mean that cognition and affect are actually independent from a social-cognitive perspective. Forgas (1995) and others (e.g., Fiske \& Taylor, 1991) have argued that cognition can be affect-laden and that affect can be infused by cognition. Nevertheless, in the United States, such distinctions are made among laypersons in understanding social conflict.

2. Japanese conflict episodes were translated into English (for U.S. participants) and U.S. conflict episodes were translated into Japanese (for Japanese participants) and were then backtranslated by different translators. A complete description of the conflicts, in both English and Japanese, can be obtained from Michele J. Gelfand.

3. Configurations were also examined in both two and four dimensions, including an analysis of the ordering of the conflicts and the multiple regression analysis for both of these solutions (on both sets of conflict episodes and for both sets of participants). These solutions did not provide as clear of an interpretation as the three-dimensional solution, as we expected on the basis of the results of the stress values. Therefore, the three-dimensional solution was preferred.

4. This view is consistent with the notion that schemas can be not only chronic (i.e., akin to "traits") but also induced by the situational context (i.e., akin to "states"; Fiske \& Taylor, 1991).

5. We thank an anonymous reviewer for suggestions along these lines. 


\section{References}

Anderson, C. A., Lindsay, J. J., \& Bushman, B. J. (1999). Research in the psychological laboratory: Truth or triviality? Current Directions in Psychological Science, 8, 3-9.

Averill, J. R. (1983). Studies on anger and aggression. American Psychologist, 38, 1145-1160.

Bazerman, M. H., \& Carroll, J. S. (1987). Negotiator cognition. In B. M. Staw \& L. L. Cummings (Eds.), Research in organizational behavior (Vol. 9, pp. 247-288). Greenwich, CT: JAI Press.

Bazerman, M. H., \& Neale, M. A. (1983). Heuristics in negotiation: Limitations to effective dispute resolution. In M. H. Bazerman \& R. J. Lewicki (Eds.), Negotiating in organizations (pp. 51-67). Beverly Hills, CA: Sage.

Benedict, R. (1946). The chrysanthemum and the sword: Patterns of Japanese culture. Boston: Houghton Mifflin.

Brett, J. M., \& Okumura, T. (1998). Inter- and intracultural negotiations: U.S. and Japanese negotiators. Academy of Management Journal, 41, 495-510.

Cohen, R. (1991). Negotiating across cultures. Washington, DC: U.S. Institute of Peace.

Cushman, P. (1995). Ideology obscured: Political uses of the self in Daniel Stern's infant. In N. R. Goldberger \& J. B. Veroff (Eds.), The culture and psychology reader (pp. 384-416). New York: New York University Press.

Drake, L., \& Donohue, W. A. (1994, June). Issue development as negotiated order in conflict. Paper presented at the annual meeting of the International Association for Conflict Management, Eugene, OR. 
Erez, M. (1994). Toward a model of cross-cultural industrial and organizational psychology. In H. C. Triandis, M. Dunnette, \& L. M. Hough (Eds.), Handbook of industrial and organizational psychology (2nd ed., Vol. 4, pp. 559-608). Palo Alto, CA: Consulting Psychologists Press.

Fiedler, F. E., Mitchell, T. R., \& Triandis, H. C. (1971). The culture assimilator: An approach to crosscultural training. Journal of Applied Psychology, 55, 95-102.

Fisher, R., \& Ury, W. (1981). Getting to yes: Negotiating an agreement without giving in. Boston: Houghton Mifflin.

Fiske, S. T., \& Taylor, S. E. (1991). Social cognition. New York: McGraw- Hill.

Forgas, J. P. (1995). Mood and judgment: The affect infusion model (AIM). Psychological Bulletin, 117, 39-66.

Forgas, J. P., \& Bond, M. H. (1985). Cultural influences on the perception of interaction episodes. Personality and Social Psychology Bulletin, 11, 75-88.

Geertz, C. (1973). The interpretation of cultures. New York: Basic Books.

Gelfand, M. J., \& Dyer, N. (2000). Cultural perspectives on negotiation: Progress, pitfalls, and prospects. Applied Psychology: An International Review, 41, 62-99.

Gibson, J. J. (1979). The ecological approach to visual perception. Boston: Houghton Mifflin.

Goffman, E. (1974). Frame analysis: An essay on the organization of experience. Cambridge, MA: Harvard University Press.

Gray, B. (1994). The gender-based foundations of negotiation theory. In R. J. Lewicki, B. H. Sheppard, \& R. Bies (Eds.), Research on negotiation in organizations (Vol. 4, pp. 3-36). Greenwich, CT: JAI Press. 
Herskovits, M. J. (1955). Cultural anthropology. New York: Knopf.

Ho, D. Y. F. (1973). Changing interpersonal relationships in Chinese families. In H. E. White (Ed.), An anthology of seminar papers: The changing family. East and West (pp. 103-118). Hong Kong: Hong Kong Baptist College.

Hofstede, G. (1980). Culture's consequences: International differences in work related values. Beverly Hills, CA: Sage.

Kashima, Y., \& Callan, V. J. (1994). The Japanese work group. In H. C.

Triandis, M. Dunnette, \& L. M. Hough (Eds.), Handbook of industrial and organizational psychology (2nd ed., Vol. 4, pp. 609-626). Palo Alto, CA: Consulting Psychologists Press.

Kelley, H., \& Thibaut, J. W. (1978). International relations: A theory of interdependence. New York: Wiley.

Kihlstrom, J., \& Klein, S. (1994). The self as knowledge structure. In R. S. Wyer, Jr. \& T. K. Srull (Eds.), Handbook of social cognition (2nd ed., Vol. 1, pp. 153-208). Hillsdale, NJ: Erlbaum.

Kim, U. (1994). Individualism and collectivism: Conceptual clarification and elaboration. In U. Kim, H. C. Triandis, C. Kagitcibasi, S. C. Choi, \& G. Yoon (Eds.), Individualism and collectivism: Theory, method, and applications (pp. 19-40). Thousand Oaks, CA: Sage.

Kitayama, S., Markus, H. R., Matsumoto, H., \& Norasakkunkit, V. (1997). Individual and collective processes in the construction of the self: Self-enhancement in the United States and selfcriticism in Japan. Journal of Personality and Social Psychology, 72, 1245-1267.

Krauss, E. S., Rohlen, T., \& Steinhoff, P. G. (1984). Conflict: An approach to the study of Japan. In E. S. Krauss, T. P. Rohlen, \& P. G. Steinhoff (Eds.), Conflict in Japan (pp. 3-15). Honolulu: University of Hawaii Press. 
Kruskal, J. B., \& Wish, M. (1978). Multidimensional scaling. Beverly Hills, CA: Sage.

Landrine, H. (1995). Clinical implications of cultural differences: The referential versus the indexical self. In N. R. Goldberger \& J. B. Veroff (Eds.), The culture and psychology reader (pp. 744-766). New York: New York University Press.

Lebra, T. S. (1984). Nonconfrontational strategies for the management of interpersonal conflicts. In E. S. Krauss, T. P. Rohlen, \& P. G. Steinhoff (Eds.), Conflict in Japan (pp. 41-60). Honolulu: University of Hawaii Press.

Leung, K. (1997). Negotiation and reward allocations across cultures. In P. C. Barley \& M. Erez (Eds.), New perspectives on international industrial/organizational psychology (pp. 640-675). San Francisco: Jossey-Bass.

Locke, E. A. (1986). Generalizing from laboratory to field settings. Lexington, MA: Lexington Books.

Lonner, W. J. (1980). The search for psychological universals. In H. C. Triandis (Ed.), Handbook of crosscultural psychology (1st ed.. Vol. 1, pp. 143-204). Boston: Allyn \& Bacon.

Lord, R. G., \& Maher, K. J. (1991). Cognitive theory in industrial and organizational psychology. In M. D. Dunnette \& L. M. Hough (Eds.) Handbook of industrial and organizational psychology (2nd ed. Vol. 2, pp. 1-62). Palo Alto, CA: Consulting Psychologists Press.

Markus, H. R., \& Kitayama, S. (1991). Culture and the self: Implications for cognition, emotion, and motivation. Psychological Review, 98, 224- 253.

Markus, H. R., Kitayama, S., \& Heiman, R. J. (1997). Culture and "basic" psychological principles. In E. T. Higgins \& A. W. Kruglanski (Eds.), Social psychology: Handbook of basic principles (pp. 857-913). New York: Guilford Press. 
Marsella, A. J., DeVos, G., \& Hsu, F. L. K. (1985). Culture and self. New York: Tavistock.

Matsumoto, D., Kudoh, T., Scherer, K., \& Wallbott, H. (1988). Antecedents of and reactions to emotions in the United States and Japan. Journal of Cross-Cultural Psychology, 19, 267-286.

McArthur, L. Z., \& Baron, R. M. (1983). Toward an ecological theory of social perception. Psychological Review, 90, 215-238.

McGrath, J. E., Martin, J., \& Kulka, R. A. (1982). Judgment calls in research. Beverly Hills, CA: Sage.

Miller, J. G., Bersoff, D. M., \& Harwood, R. L. (1990). Perceptions of social responsibilities in India and the United States: Moral imperatives or personal decisions? Journal of Personality and Social Psychology, 58, 33-47.

Neale, M. A., \& Bazerman, M. H. (1991). Negotiator cognition and rationality. New York: Free Press.

Ohbuchi, K., \& Takahashi, Y. (1994). Cultural styles of conflict management in Japanese and Americans: Passivity, covertness, and effectiveness of strategies. Journal of Applied Social Psychology, 24, 1345-1366.

Pelled, L. H., Eisenhardt, K. M., \& Xin, K. R. (1999). Exploring the black box: An analysis of work group diversity, conflict, and performance. Administrative Science Quarterly, 44, 1-28.

Pinkley, R. L. (1990). Dimensions of conflict frame: Disputants' interpretations of conflict. Journal of Applied Psychology, 75, 117-126.

Pinkley, R. L. (1992). Dimensions of conflict frame: Relation to disputant perceptions and expectations. International Journal of Conflict Management, 5, 95-113.

Pruitt, D. G., \& Carnevale, P. J. (1993). Negotiation in social conflict. Pacific Grove, CA: Brooks/Cole. 
Putnam, L. L., \& Holmer, M. (1992). Framing, refraining, and issue development. In L. L. Putnam \& M. E. Roloff (Eds.), Communication and negotiation (pp. 128-155). Newbury Park, CA: Sage.

Raiffa, H. (1982). The art and science of negotiation. Cambridge, MA: Harvard University Press.

Schwartz, S. H. (1994). Beyond individualism/collectivism: New cultural dimensions of values. In U. Kim, H. C. Triandis, C. Kagitcibasi, S. C. Choi, \& G. Yoon (Eds.), Individualism and collectivism: Theory, method, and applications (pp. 85-122). Thousand Oaks, CA: Sage.

Sheppard, B., Blumenfeld-Jones, J., \& Minton, J. (1987). To control or not to control: Two models of conflict intervention. Unpublished manuscript.

Shweder, R. A., \& Bourne, E. J. (1982). Does the concept of the person vary cross-culturally? In A. J. Marsella \& G. M. White (Eds.), Cultural conceptions of mental health and therapy (pp. 97-137). London: Reidel.

Smith, P. B., \& Bond, M. H. (1999). Social psychology across cultures. Boston: Allyn \& Bacon.

Strauss, C., \& Quinn, N. (1997). A cognitive theory of cultural meaning. New York: Cambridge University Press.

Thompson, L. L. (1990). Negotiation behavior and outcomes: Empirical evidence and theoretical issues. Psychological Bulletin, 108, 515-532.

Thompson, L. L., \& Hastie, R. (1990). Social perception in negotiation. Organizational Behavior and Human Decision Processes, 47, 98-123.

Thompson, L., \& Loewenstein, G. (1992). Egocentric interpretations of fairness and interpersonal conflict. Organizational Behavior and Human Decision Processes, 51, 176-197. 
Ting-Toomey, S. (1990). Toward a theory of conflict and culture, hi W. Gudykunst, L. Stewart, \& S. TingToomey (Eds.), Communication, culture, and organizational processes (pp. 71-86). Beverly Hills, CA: Sage.

Ting-Toomey, S. (1994). Managing conflict in intimate intercultural relationships. In D. D. Cahn (Ed.), Conflict in personal relationships (pp. 47-77). Hillsdale, NJ: Erlbaum.

Tinsley, C. H., \& Brett, J. M. (1997). Managing work place conflict: A comparison of conflict frames and resolutions in the U.S. and Hong Kong. In L. N. Dosier \& J. B. Keys (Eds.), Academy of Management proceedings (pp. 87-91). Statesboro: Georgia Southern University, College of Business Administration, Office of Publications and Faculty Research Services.

Triandis, H. C. (1972). An analysis of subjective culture. New York: Wiley.

Triandis, H. C. (1983). Essentials of studying cultures. In D. Landis \& R. Brislin (Eds.), Handbook of intercultural training (Vol. 1, pp. 82-117). New York: Pergamon Press.

Triandis, H. C. (1989). The self and social behavior in differing cultural contexts. Psychological Review, 96, 506-520.

Triandis, H. C. (1995). Individualism and collectivism. New York: Simon \& Schuster.

Triandis, H. C., McCusker, C., \& Hui, C. H. (1990). Multimethod probes of individualism and collectivism. Journal of Personality and Social Psychology, 59, 1006-1020.

Walton, R. E., \& McKersie, R. (1965). A behavioral theory of labor negotiations: An analysis of a social interaction system. New York: McGraw-Hill

Weiner, B. (1986). An attributional theory of motivation and emotion. New York: Springer-Verlag. 
Wish, M., Deutsch, M., \& Kaplan, S. J. (1976). Perceived dimensions of interpersonal relations. Journal of Personality and Social Psychology, 33, 409-420. 
Table 1

Multiple Correlations and F Ratios of Potential Labels in Three Dimensions for Both U.S. and Japanese Conflicts as Construed by American and Japanese Participants

\begin{tabular}{|c|c|c|c|c|c|c|c|c|}
\hline \multirow[b]{3}{*}{ Conflict } & \multicolumn{4}{|c|}{ U.S. conflicts } & \multicolumn{4}{|c|}{ Japanese conflicts } \\
\hline & \multicolumn{2}{|c|}{ U.S. participants } & \multicolumn{2}{|c|}{$\begin{array}{l}\text { Japanese } \\
\text { participants }\end{array}$} & \multicolumn{2}{|c|}{ U.S. participants } & \multicolumn{2}{|c|}{$\begin{array}{c}\text { Japanese } \\
\text { participants }\end{array}$} \\
\hline & $\boldsymbol{R}^{2}$ & $F(3,24)$ & $R^{2}$ & $F(3,24)$ & $R^{2}$ & $F(3,24)$ & $R^{2}$ & $F(3,24)$ \\
\hline $\begin{array}{l}\text { The conflict requires a compromise or mutual } \\
\text { cooperation. }\end{array}$ & .29 & $3.26^{*}$ & .63 & $13.53^{* *}$ & .67 & $16.13 * *$ & .84 & $40.65^{* *}$ \\
\hline $\begin{array}{l}\text { The conflict requires a concession by one party. } \\
\text { One party is right and the other is wrong. }\end{array}$ & .64 & $14.37 \times k$ & .53 & $9.16^{* *}$ & .28 & $3.10^{*}$ & .66 & $15.65^{4 *}$ \\
\hline $\begin{array}{l}\text { The conflict is based on interpersonal issues. } \\
\text { Involves problems with the relationship. } \\
\text { The conflict is based on nonrelationship issues. }\end{array}$ & .14 & 1.30 & .22 & 2.31 & .31 & $3.66^{*}$ & .34 & $4.08^{*}$ \\
\hline $\begin{array}{l}\text { Imvolves specific issues ocher than those } \\
\text { dealing with the relationship } \\
\text { The conflict is csused by one of the parties }\end{array}$ & .10 & 0.92 & .16 & 1.48 & .31 & $3.55^{+}$ & .31 & $3.61^{*}$ \\
\hline $\begin{array}{l}\text { (i.e., one party is responsible of is to blame). } \\
\text { The conflet is caused by both parties (i.e., bort }\end{array}$ & .50 & $8.00^{\mathrm{k} *}$ & 61 & $12.63 \% *$ & .65 & $14.98 * *$ & .75 & $24,43^{* *}$ \\
\hline $\begin{array}{l}\text { parties are responsible or to blame for the } \\
\text { conflict). }\end{array}$ & 41 & $5.55^{* *}$ & 53 & $9.08 \times x$ & .63 & $13.35^{* *}$ & .60 & $11,88^{* *}$ \\
\hline $\begin{array}{l}\text { The conflict is emotional (i.e., there is a focus } \\
\text { on the feelings involved, such as jealoesy. } \\
\text { hatred, anger, frustration, ecc.). }\end{array}$ & .53 & $9.15^{\mathrm{k*}}$ & 37 & $4.72^{* *}$ & .27 & $3.00^{*}$ & .21 & 2.16 \\
\hline $\begin{array}{l}\text { The conflict is intellectual (Le., there is a focus } \\
\text { on the facts/thoughts involved). } \\
\text { The conflict reflects morat considerations (what }\end{array}$ & .39 & $5.02^{k *}$ & .42 & $5.81 * x$ & .63 & $13.34 * *$ & .63 & $13.59 * *$ \\
\hline $\begin{array}{l}\text { is right versias wrong). } \\
\text { The conflict iavolves considerations of honor. }\end{array}$ & .50 & $7.86^{* *}$ & 38 & $4.98^{* x}$ & .47 & $6.99 * *$ & .62 & $12.90^{\circ 0}$ \\
\hline $\begin{array}{l}\text { reputation, of digniry (i.e., saving face, giving } \\
\text { face). }\end{array}$ & .24 & 2.46 & 29 & $3.30^{*}$ & .63 & $13.42 * *$ & .44 & $6.22^{* *}$ \\
\hline $\begin{array}{l}\text { The conflict is covert (one or both parties are } \\
\text { hiding their true feelings). }\end{array}$ & .17 & 1.67 & 30 & $3.42^{*}$ & .40 & $5.26 * *$ & .67 & $16.08 * *$ \\
\hline $\begin{array}{l}\text { The contlict involves a relationship between } \\
\text { parties of different status. } \\
\text { The conflict involves a confrontation (i.e., is }\end{array}$ & .03 & 0.23 & .06 & 0.49 & .71 & $19.14^{* * *}$ & .46 & $6.72^{* *}$ \\
\hline & .12 & 1.05 & 38 & $4.99 * x$ & .71 & $19.35^{* *}$ & .70 & $18.59^{* * 4}$ \\
\hline $\begin{array}{l}\text { berween individuals or within groups. } \\
\text { The conflict involves clashes between an }\end{array}$ & 28 & $3.05 *$ & .39 & $5.20 * *$ & .15 & 1.46 & .15 & 1.46 \\
\hline $\begin{array}{l}\text { individual's interests and a group's interests. } \\
\text { The conflict revolves around an individual's }\end{array}$ & .30 & $3.38^{*}$ & .14 & 1.28 & .21 & 2.13 & .01 & 0.11 \\
\hline $\begin{array}{l}\text { sense of duties and obligations. } \\
\text { The conflict focuses on social noms (e.g. }\end{array}$ & .75 & $23.79 * *$ & .45 & $6.65^{* *}$ & .46 & $6.91 * *$ & .36 & $4.56^{*}$ \\
\hline $\begin{array}{l}\text { appropriate behavior). } \\
\text { The conflict is related to feelings of guilt or }\end{array}$ & .48 & $7.52^{* *}$ & .44 & $6.33^{* *}$ & .38 & $4.92^{* *}$ & .66 & $15.78 * *$ \\
\hline $\begin{array}{l}\text { shame. } \\
\text { The conflict involves a distinction between }\end{array}$ & .65 & $15.12^{\text {te }}$ & .40 & $5.27 * *$ & .55 & $9.56 * *$ & .54 & $9.35^{+*}$ \\
\hline $\begin{array}{l}\text { ingroups and outgroups. } \\
\text { The conflict is caused by an opatside agent or }\end{array}$ & .42 & $5.71^{* 6}$ & .03 & 0.28 & .34 & $4.08^{*}$ & .03 & 0.24 \\
\hline $\begin{array}{l}\text { The conflict is caused by an oatside agent or } \\
\text { situation (e.g., a third party). } \\
\text { The conflict is resolvable (parties are perceived }\end{array}$ & .11 & 0.96 & 05 & 0.42 & .02 & 0.15 & .14 & 1.26 \\
\hline $\begin{array}{l}\text { to be willing and able to resolve the conflict). } \\
\text { The conflict involves threats to one's }\end{array}$ & .16 & 1.49 & 20 & 1.95 & .15 & 1.38 & .49 & $7.78 * *$ \\
\hline $\begin{array}{l}\text { independence of thought or freedom of } \\
\text { choice } \\
\text { The conflict revolves around challenges to }\end{array}$ & .48 & $7.40^{*}$ & .13 & 1.29 & .31 & $3.60^{*}$ & .23 & 2.44 \\
\hline one's antonomy." & .46 & $6.72^{*}$ & .14 & 1.31 & .30 & $3.10^{*}$ & .25 & 2.73 \\
\hline $\begin{array}{l}\text { The conflict reflects a direct infringement of } \\
\text { one person's persobal rights." } \\
\text { The conflict involves what one person feels }\end{array}$ & .27 & $3.00^{*}$ & .08 & 0.72 & .15 & 1.43 & .16 & 1.52 \\
\hline $\begin{array}{l}\text { The contict involves what one person feels } \\
\text { they are rightually entited." }\end{array}$ & .30 & $3.37^{*}$ & .17 & 1.64 & .20 & 1.80 & .16 & 1.62 \\
\hline
\end{tabular}




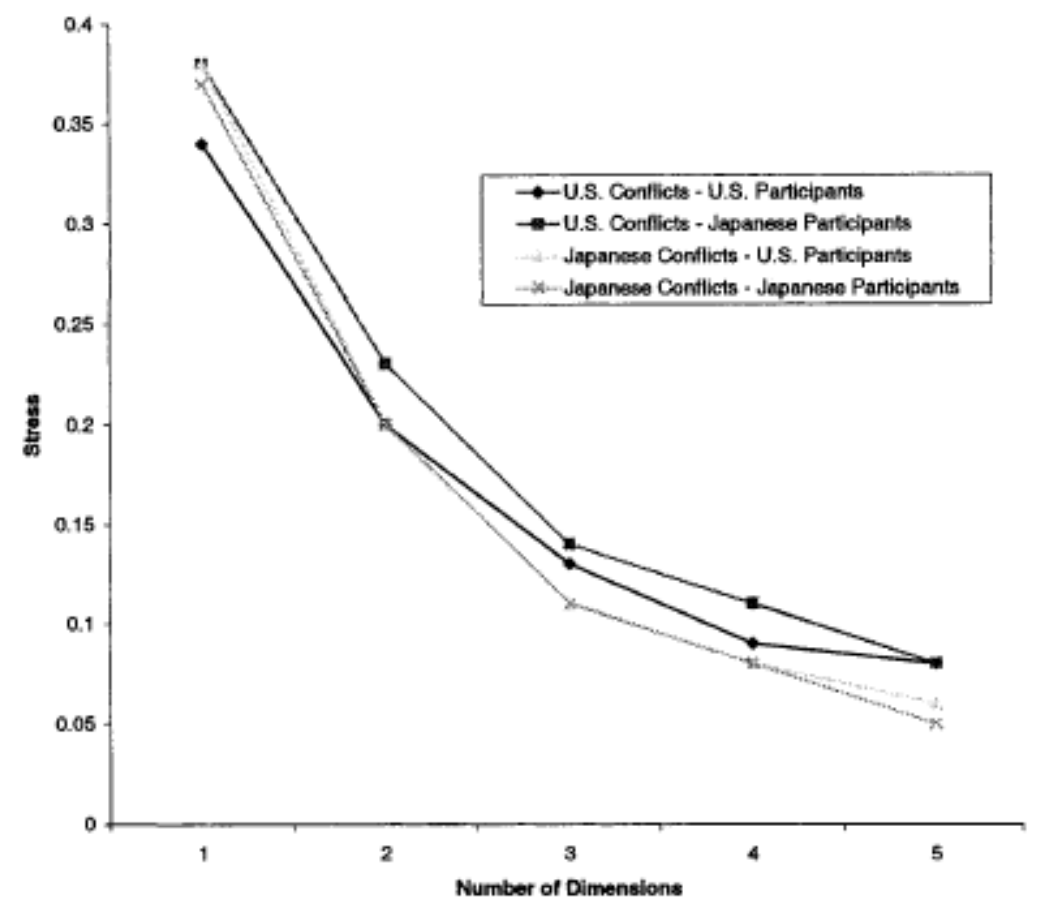

Figure l. Stress values for each multidimensional space.

Table 2

Overview of All Dimension Labels in the Four Multidimensional Scaling Spaces

\begin{tabular}{lll}
\hline & & \multicolumn{1}{c}{ Conflicts } \\
\cline { 2 - 3 } Participants & \multicolumn{1}{c}{ U.S. } & \multicolumn{1}{c}{ Japanese } \\
\hline American & $\begin{array}{l}\text { Compromise vs. win } \\
\text { Intelloctual vs. emotional } \\
\text { Infringerments to the self }\end{array}$ & $\begin{array}{l}\text { Campromise vs. win } \\
\text { Intellectual vs. emotional } \\
\text { Overt vs. covert }\end{array}$ \\
Japanese & $\begin{array}{l}\text { Compromise vs. win } \\
\text { Giri violations } \\
\text { Differentiation of self from others }\end{array}$ & $\begin{array}{l}\text { Compromise vs. win } \\
\text { Giri violations } \\
\text { Over vs. covert }\end{array}$ \\
\hline
\end{tabular}

Note. Italicized values illustrate a strong universal conflict frame (across samples and conflicts). 
Table 3

Standardized Beta Values (Regression Weights) of Potential Labels in Three Dimensions for U.S. Conflicts as Construed by American and Japanese Participants

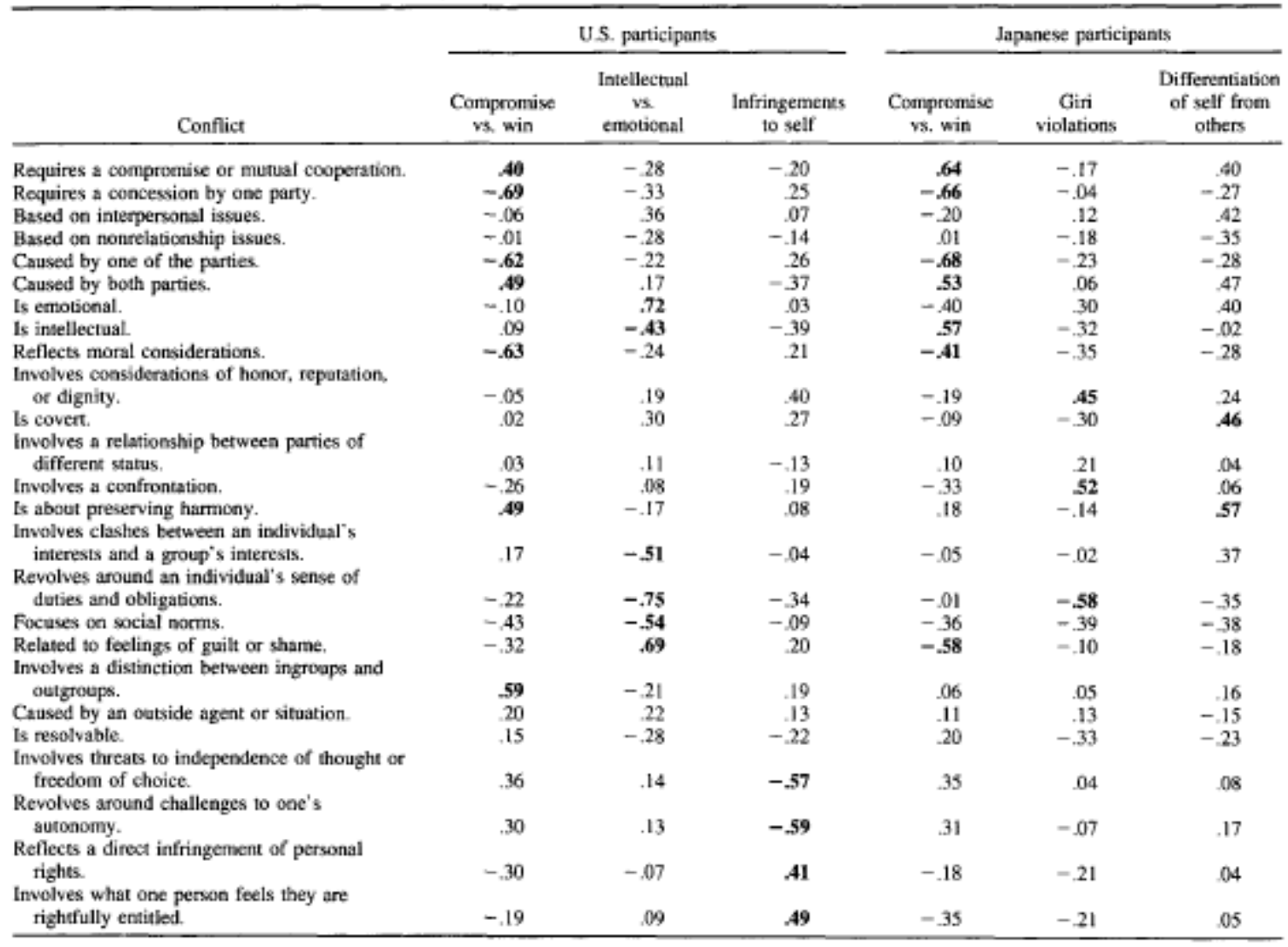

Note. Values in boldface are significant at $p<.05$ and were used to interpret the dimensions. 
Table 4

Standardized Beta Values (Regression Weights) of Potential Labeis in Three Dimensions for Japanese Conflicts as Construed by American and Japanese Participants

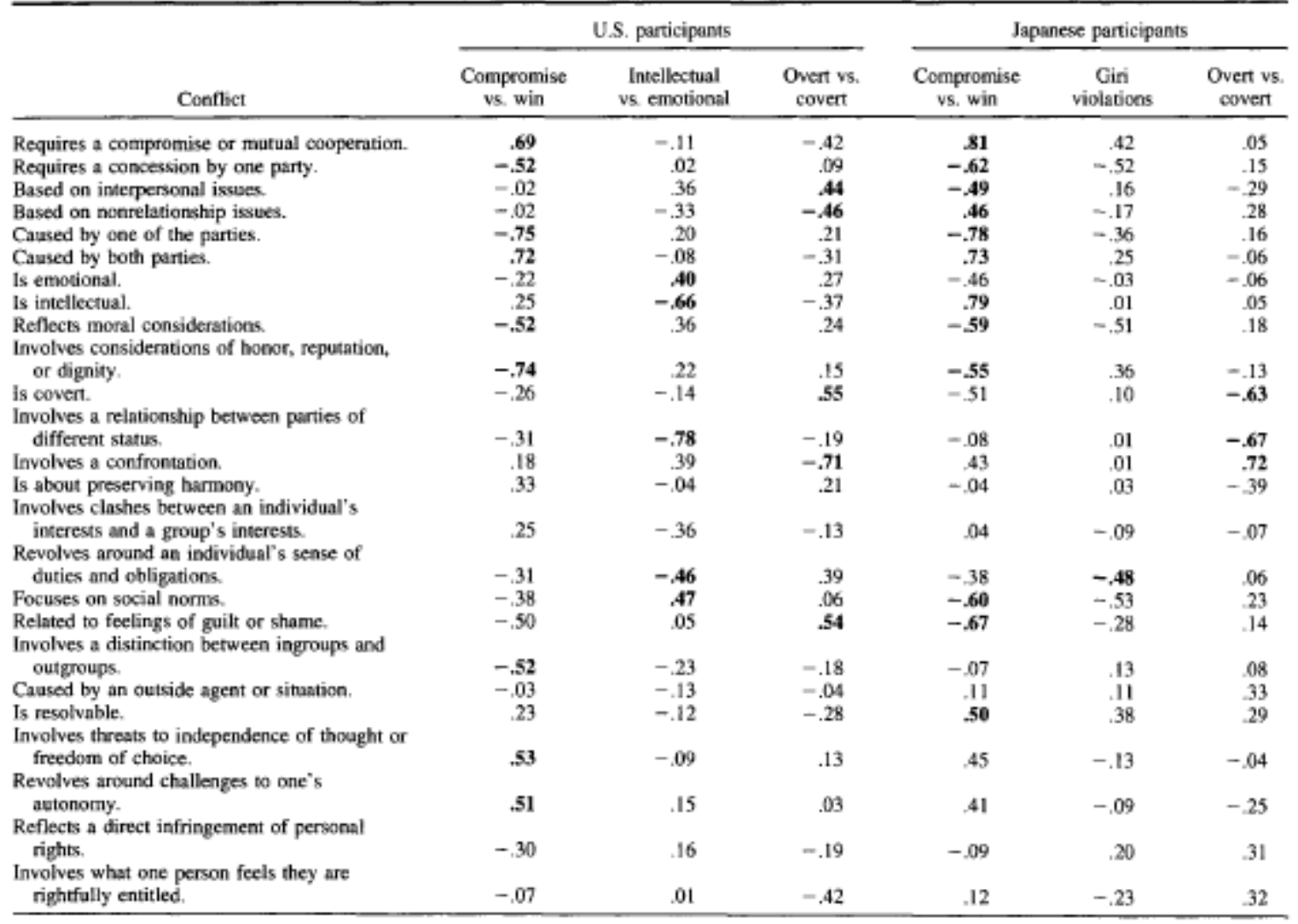

Nore. Values in boldface are significant at $\rho<.05$ and were used to interpret the dimensions. 